\title{
Different Aspects of Kidney Function in Well-Controlled Congenital Hypothyroidism
}

\author{
Alaleh Gheissari1, Mahin Hashemipour2, Pooya Khosravi3, Atoosa Adibi4 \\ IIUMS, Pediatric Nephrology, Isfahan, Iran, Islamic Republic of \\ 2Isfahan University of Medical Sciences, Pediatric Endocrinology, Isfahan, Iran, Islamic Republic of \\ 3/sfahan University of Medical Sciences, Pediatrics, Isfahan, Iran, Islamic Republic of \\ 4Isfahan University of Medical Sciences, Radiology, Isfahan, Iran, Islamic Republic of
}

\begin{abstract}
Objective: Congenital hypothyroidism (CH) increases the prevalence of kidney and urogenital malformations. There are limited studies considering different aspects of kidney function in well-controlled $\mathrm{CH}$ patients. We evaluated some features of kidney function in euthyroid children with $\mathrm{CH}$ who have been receiving thyroxine hormone since early life.

Methods: This cross-sectional study was conducted in Isfahan, Iran, on 74 children aged 2-15 years old (36 $\mathrm{CH}$ patients and 38 healthy children). Inclusion criteria for $\mathrm{CH}$ patients were euthyroidism at the time of the survey and initiation of replacement therapy during the early neonatal period. Kidney ultrasound evaluation was performed in all participants. Serum biochemistry included urea, creatinine, sodium $(\mathrm{Na})$, potassium $(\mathrm{K})$, magnesium, calcium, and cystatin $\mathrm{C}$ levels. Urine electrolytes, fraction excretion (FE) of electrolytes and microalbumin, and glomerular filtration rate (GFR) were also determined.

Results: The male/female ratio was $0.8 / 1$ and $1.5 / 1$ in the patient and control groups, respectively. Mean age and height did not differ significantly between the two groups. Ultrasound evaluation of the kidney revealed that the anteroposterior diameter of the right kidney was significantly higher in $\mathrm{CH}$ patients as compared to healthy subjects. No significant difference was observed between GFRs in patients with $\mathrm{CH}$ and healthy children. The mean values for FENa and FEK were significantly higher in the patient group.

Conclusions: Increased FENa and FEK may be a manifestation of impaired tubular maturation in $\mathrm{CH}$. More longitudinal studies are needed to evaluate kidney function in $\mathrm{CH}$ patients.

Key words: Congenital hypothyroidism, kidney function, kidney size
\end{abstract}

Conflict of interest: None declared

Received: 17.08.2012
Accepted: 08.10.2012

\section{Introduction}

Thyroid hormones are of prime importance in human growth and development. Congenital thyroxine (T4) deficiency or insufficiency in the newborn results in severe mental retardation $(1,2,3)$. Reported prevalence of congenital hypothyroidism $(\mathrm{CH})$ varies between $1 / 748$ and 1/10 000 . These figures differ by geographic area and applied testing strategies $(4,5,6,7)$.

The incidence of several congenital malformations including cardiac, oral, neurologic, and urogenital anomalies have been reported to be higher in $\mathrm{CH}$ patients in comparison with a normal population $(8,9,10)$. $\mathrm{CH}$ increases the prevalence of renal and urogenital malformations (odds ratio: 13.2) (8). In addition, a delay in the treatment of $\mathrm{CH}$ or incomplete $\mathrm{T} 4$ replacement therapy in these patients may affect kidney size (1). The role of thyroid hormones on kidney tubular function and on the renin-angiotensin-aldosterone system has been studied by several groups $(11,12)$. However, the effect of T4 replacement therapy shortly after birth on preservation of kidney function has not been investigated in depth. A neonatal thyroid screening program is being conducted in Isfahan since 2002. Following the initiation of this program, a notable decrease has been observed in the incidence of undiagnosed and uncontrolled $\mathrm{CH}$ cases. On the other hand, studies investigating the different aspects of kidney function in well-

\section{Address for Correspondence}

Alaleh Gheissari MD, IUMS, Pediatric Nephrology, Isfahan, Iran, Islamic Republic of Phone: +983112502462 E-mail: gheisari@med.mui.ac.ir

Journal of Clinical Research in Pediatric Endocrinology, Published by Galenos Publishing. 
controlled $\mathrm{CH}$ patients are limited. In the present study, we evaluated different features of kidney function in euthyroid children born with $\mathrm{CH}$ and treated with $\mathrm{T} 4$ hormone started shortly after birth.

\section{Methods}

This cross-sectional study on 74 children aged 2-15 years was conducted in Isfahan, Iran, from March 2010 to October 2011. Thirty-six subjects were known cases of $\mathrm{CH}$ who met the inclusion criteria of being euthyroid at the time of the survey and having received replacement therapy initiated in the early neonatal period (within the first 14 days of life). Thirty eight age-, weight- and height-matched healthy children were selected as the control group. Information on this group was based on their medical records and interviews conducted with their parents. Due to the scarcity of poorly controlled $\mathrm{CH}$ patients in the community, we were not able to recruit such patients to the study as another control group.

Kidney ultrasound was performed in each participant by the same experienced radiologist blinded to the diagnosis of $\mathrm{CH}$ using an ultrasound apparatus with 3 and $6 \mathrm{MHz}$ curvy linear probes (Voluson 730 Expert, GE Medical Systems, Milwaukee, WI, USA). All three dimensions of each kidney (length, width, and height), as well as the anterior-posterior (AP) diameter of the pelvis, renal parenchymal thickness, and bladder wall thickness were measured. An AP diameter greater than $3 \mathrm{~mm}$ and a bladder wall thickness greater than 2 $\mathrm{mm}$ were accepted as high for all ages. Fasting blood samples were collected in all subjects to measure cystatin $C$, blood urea nitrogen $(\mathrm{BUN})$, creatinine $(\mathrm{Cr})$, magnesium $(\mathrm{Mg})$, sodium $(\mathrm{Na})$, potassium (K), and calcium (Ca). Urine $\mathrm{Cr}, \mathrm{Mg}, \mathrm{Na}, \mathrm{K}, \mathrm{Ca}$, and microalbumin (MA) were measured in the fasting spot urine samples. MA was assessed by the nephelometric (turbidimetric) method, using a locally manufactured kit (ParsAzmoon, kit number 2055015, Iran). A urine $\mathrm{MA} / \mathrm{Cr}$ ratio greater than 30 was considered abnormally high. Serum $\mathrm{Cr}$, $\mathrm{Mg}, \mathrm{Ca}$, and BUN were measured enzymatically on a Hitachi 7350 autoanalyzer. Serum cystatin C was measured by a particle-enhanced immunoturbidimetric method (Dako, Denmark). Fractional excretion (FE) of $\mathrm{Na}$ and $\mathrm{K}$ (FENa and FEK) were used to detect presence of renal tubular dysfunction. Additionally FEMg was used as a marker of tubular injury $(13,14,15)$. We used the following formulae to calculate FENa, FEK, and FEMg (13):

$$
\begin{aligned}
& F E(X)=[\text { serum } \mathrm{Cr} \times \text { urinary }(X) / \text { serum }(X) \times \text { urinary } \mathrm{Cr}] \times 100 \\
& F E M g=[\text { serum } \mathrm{Cr} \times \text { urinary }(\mathrm{Mg}) / \text { serum }(\mathrm{Mg}) \times \text { urinary } \\
& \mathrm{Cr} \times 0.7] \times 100
\end{aligned}
$$

It has been shown previously that FEMg measurements can be used to demonstrate any possible damage in the thick ascending limb of Henle's loop which is one of the most energy-dependent sections of the renal tubule $(14,15)$.

Glomerular filtration rate (GFR) was measured using the following formulae:

1) GFR (Schwartz formula) $=\mathrm{K} \times$ height $(\mathrm{cm}) /$ serum $\mathrm{Cr}$ (mg/dL) (16)

( $K=0.55$ for girls and $K=0.7$ for boys)

2) GFR (mL/min/1.73 $\mathrm{m}^{2}$ ) (cystatin C-based Schwartz

formula) $=39.1$ height $(\mathrm{m}) / \mathrm{SCr}(\mathrm{mg} / \mathrm{dL})]^{0.516}[1.8 /$ cystatin

C (mg/L)]0.294 [30/BUN(mg/dL)]0.169 [1.099(male)]

[height (m)/1.4]0.188 (16).

3) GFR (cystatin C-based formula) $=84.69 \times$ cystatin $\mathrm{C}$

$(\mathrm{mg} / \mathrm{L})-1.680 \times 1.384(17)$

4) Log GFR (cystatin C-based formula) $=1.962+1.123$ _ log (1/cystatin C) (18)

Using the above equations enabled us to compare the GFR results by sex, height, and age.

Euthyroid state was defined as a normal response to thyroid-stimulating hormone (TSH) and normal T4 levels. In all $\mathrm{CH}$ patients included in the study, serum TSH values were kept at levels less than $5 \mathrm{mU} / \mathrm{L}$ and serum total T4 and free T4 during the first year of life within targeted values (130-206 $\mathrm{nmol} / \mathrm{L}$ or $10-16 \mu \mathrm{g} / \mathrm{dL}$ and $18-30 \mathrm{pmol} / \mathrm{L}$ or $1.4-2.3 \mathrm{ng} / \mathrm{dL}$, respectively) (19).

The study protocol was approved by the Research Ethics Committee at Isfahan University of Medical Sciences. Written consent was obtained from each subject's parents or caregivers, and also oral consent was taken from the participants, when appropriate.

\section{Results}

There were 20 females and 16 males in the study group (male/female ratio 0.8/1). There were 23 males and 15 females in the control group (male/female ratio 1.5/1). The mean age did not differ significantly between the study and control groups $(9.2 \pm 3.6$ vs. $9.1 \pm 4.1$ years, respectively; $p>0.05)$. Mean \pm standard deviation (SD) values for height in the study and control groups were $132.9 \pm 21.7 \mathrm{~cm}$ and $131.0 \pm 20.8$ $\mathrm{cm}$, respectively $(p>0.05)$. Height SD scores were also similar in the study and control groups $(0.00 \pm 1.00$ vs. $0.00 \pm 0.00$, respectively; $\mathrm{p}<0.05)$. The median age at diagnosis and treatment in $\mathrm{CH}$ male and female patients were 10 and 14 days, respectively.

Kidney ultrasound results revealed that only AP diameter of the right kidney was significantly increased in $\mathrm{CH}$ patients as compared to healthy subjects (Table 1). Kidney echogenicity was normal in both groups. Bladder wall thickness was 
comparable in the two groups $(1.05 \pm 0.23 \mathrm{~mm}$ in the patients vs. $1.05 \pm 0.22 \mathrm{~mm}$ in controls, $\mathrm{p}>0.05)$. A bladder wall thickness of more than $2 \mathrm{~mm}$ was observed in one patient with $\mathrm{CH}$ and in two subjects in the control group. A post-void residual urine volume of more than $10 \mathrm{~mL}$ was observed in one child with $\mathrm{CH}$. A distal ureter diameter greater than $3 \mathrm{~mm}$ was also observed in one patient.

The mean levels of serum $\mathrm{Na}, \mathrm{K}, \mathrm{Mg}$ and $\mathrm{Cr}$ and the mean levels of urinary $\mathrm{Na}, \mathrm{K}, \mathrm{Mg}$, and $\mathrm{Cr}$ were not significantly different between the study and control groups (data not shown). As shown in Table 2, the mean values for GFR, irrespective of the formula used for GFR calculation, were also comparable in patients and controls. In addition, the mean $1 /$ cystatin $C$ levels did not differ significantly between the two groups. The mean values for FENa and FEK were significantly higher in the study group (Table 2). No significant difference was observed in urinary $\mathrm{Ca} / \mathrm{Cr}$ and urinary $\mathrm{MA} / \mathrm{Cr}$ ratio between the two groups.

Since kidney measurements, serum $\mathrm{Cr}$ and GFR values all increase with age, we used SD scores to evaluate these parameters. Comparing SD scores for bladder wall thickness, serum $\mathrm{Cr}$ and GFR between the patient and control groups did not show any significant differences, except for the SD score of the kidney AP diameter being higher in the study group than in the control group (Table 3).

\section{Discussion}

In this present study, we evaluated the anatomical and functional aspects of kidneys in well-treated $\mathrm{CH}$ children.

Table 1. Kidney measurements in children with congenital hypothyroidism (CH) and in the control group (mean $\pm \mathrm{SE}$ )

\begin{tabular}{|c|c|c|c|c|c|c|}
\hline & \multicolumn{2}{|c|}{ Children with $\mathrm{CH}$} & \multicolumn{2}{|c|}{ Controls } & \multicolumn{2}{|c|}{ Significance } \\
\hline & Left kidney & Right kidney & Left kidney & Right kidney & $\begin{array}{l}\text { Comparison } \\
\text { between left kidneys }\end{array}$ & $\begin{array}{l}\text { Comparison } \\
\text { between right kidneys }\end{array}$ \\
\hline Pelvic AP diameter (mm) & $1.17 \pm 0.02$ & $1.11 \pm 0.05$ & $0.9 \pm 0.01$ & $1 \pm 0.00$ & $p=0.02$ & $\mathrm{p}=0.035$ \\
\hline Kidney length (mm) & $86.69 \pm 2.14$ & $84.96 \pm 2.15$ & $84.15 \pm 1.45$ & $82.10 \pm 1.70$ & $p>0.05$ & $p>0.05$ \\
\hline Kidney width (mm) & $34.45 \pm 1.34$ & $31.18 \pm 0.85$ & $31.89 \pm 0.09$ & $30.13 \pm 0.65$ & $p>0.05$ & $p>0.05$ \\
\hline
\end{tabular}

Table 2. Markers of kidney function in children with congenital hypothyroidism (CH) and in the control group (mean \pm SE)

\begin{tabular}{|c|c|c|c|}
\hline Variable & Children with $\mathrm{CH}$ & Controls & Significance \\
\hline Serum cystatin C (mg/L) & $0.70 \pm 0.03$ & $0.67 \pm 0.02$ & NS \\
\hline Serum $\mathrm{Cr}(\mathrm{mg} / \mathrm{dL})$ & $0.67 \pm 0.02$ & $0.61 \pm 0.02$ & NS \\
\hline GFR (Schwartz formula) (mL/min/1.73m²) & $98.28 \pm 2.18$ & $98.23 \pm 2.11$ & NS \\
\hline GFR (cystatin C based-Schwartz formula) (mL/min/1.73m²) & $78.18 \pm 1.8$ & $78.55 \pm 1.34$ & NS \\
\hline 1/cystatin C & $1.49 \pm 0.06$ & $1.53 \pm 0.05$ & NS \\
\hline Log GFR [(Filler et al (18)] & $2.92 \pm 0.16$ & $2.91 \pm 0.13$ & NS \\
\hline GFR [(Grubb et al $(17)]\left(\mathrm{mL} / \mathrm{min} / 1.73 \mathrm{~m}^{2}\right)$ & $123.45 \pm 7.02$ & $128.53 \pm 5.54$ & NS \\
\hline FEK (\%) & $12.47 \pm 2.35$ & $7.09 \pm 0.82$ & $p=0.027$ \\
\hline FEMg (\%) & $4.08 \pm 0.39$ & $3.85 \pm 0.38$ & NS \\
\hline FENa (\%) & $1.01 \pm 0.1$ & $0.76 \pm 0.05$ & $p=0.046$ \\
\hline Urine $\mathrm{MA} / \mathrm{Cr}(\mathrm{mg} / \mathrm{mL} / \mathrm{mg} / \mathrm{mL})$ & $0.13 \pm 0.03$ & $0.17 \pm 0.02$ & NS \\
\hline Urine $\mathrm{Ca} /$ urine $\mathrm{Cr}(\mathrm{mg} / \mathrm{mL} / \mathrm{mg} / \mathrm{mL})$ & $0.10 \pm 0.02$ & $0.11 \pm 0.01$ & NS \\
\hline Urine $\mathrm{K} /$ urine $\mathrm{Cr}(\mathrm{mg} / \mathrm{mL} / \mathrm{mg} / \mathrm{mL})$ & $0.81 \pm 0.15$ & $0.46 \pm 0.04$ & $\mathrm{p}=0.03$ \\
\hline
\end{tabular}

Cr: creatinine, GFR: glomerular filtration rate, FENa: fractional excretion of sodium, FEK: fractional excretion of potassium, FEMg: fractional excretion of magnesium, MA: microalbumin, Ca: calcium, NS: not significant 
Gheissari $A$ et al.

Kidney Function in Congenital Hypothyroidism

Table 3. This table shows SD scores of bladder wall thickness, AP diameter, serum creatinine and GFR in the study and control two groups

\begin{tabular}{lccc}
\hline Variables & CH patients & Controls & Significance \\
\hline Bladder wall thickness & $0.02 \pm 1.01$ & $0.01 \pm 1.03$ & NS \\
Kidney AP diameter & $0.00 \pm 1.03$ & 0 & $p<0.05$ \\
Serum creatinine level (mg/dL) & $0.02 \pm 1.00$ & $0.03 \pm 1.04$ & NS \\
GFR (cystatin C-based & $0.00 \pm 1.00$ & $0.00 \pm 1.00$ & NS \\
Shwartz formula) & & & \\
\hline $\begin{array}{l}\text { GFR: glomerular filtration rate, CH: congenital hypothyroidism, SD: standard } \\
\text { deviation, AP: anterior-posterior, NS: not significant }\end{array}$ &
\end{tabular}

Reports on evaluation of kidney function in uncontrolled $\mathrm{CH}$ are scarce and we were not able to compare our results in well-controlled $\mathrm{CH}$ cases with those on poorly controlled patients. Nonetheless, our results revealed kidney dysfunction in $\mathrm{CH}$ in addition to a bilateral mild increase in the AP diameter of the kidney in $\mathrm{CH}$ patients. However, no evidence of hydronephrosis (AP diameter of $10 \mathrm{~mm}$ or more) was found. Kumar et al (8) have reported a high incidence of congenital anomalies pertaining to the heart and to the gastrointestinal and urogenital systems in $\mathrm{CH}$ patients. They demonstrated that hydronephrosis was the most prevalent renal anomaly in $\mathrm{CH}$ children (8). In another study, an increased prevalence of urogenital malformations in $\mathrm{CH}$ was reported (9). Bulbul et al (1) have suggested that a delay in diagnosis and treatment could be the mechanism responsible for the change in kidney dimensions in $\mathrm{CH}$ children. Although a mild increase in $\mathrm{AP}$ diameter was detected also in our patients, overall geometric dimensions (length and width) of the kidneys in well-treated $\mathrm{CH}$ patients were found to be comparable to those of healthy children. Considering the significant correlation of kidney size with height in children (20), we recruited age- and heightmatched healthy children as the control group in the present study.

In addition to the geometric parameters of the kidney, we also evaluated different aspects of kidney function, including GFR, urine MA, serum $\mathrm{Cr}$ levels, and FENa, FEK and FEMg. GFR assessment is one of the most important criteria for evaluation and detection of renal function impairment. Serum Cr-based Schwartz formula has been widely accepted to estimate GFR. Recently, a serum cystatin C-based equation has been developed to diminish the chance of overestimating GFR values measured by the Cr-based Schwartz formula (16). There are various equations to measure GFR based on serum cystatin C. We selected two equations that determined serum cystatin $\mathrm{C}$ with a similar technique as that used in our study (particle-enhanced immunoturbidimetric method) $(17,18)$. In addition to GFR, various markers such as FENa and FEMg have been introduced to evaluate kidney function in the normal population and in chronic kidney disease (CKD) $(14,15,21,22)$. Peralta et al (23) proposed a triple-marker approach using serum $\mathrm{Cr}$, serum cystatin $\mathrm{C}$, and microalbuminuria to screen CKD more accurately. We also added measurements of urine MA and FE of electrolytes to GFR to detect whether various aspects of kidney function differ in $\mathrm{CH}$ patients. The role of thyroid hormones on GFR has been widely discussed $(24,25,26,27)$. It has been shown that serum $\mathrm{Cr}$ and cystatin $\mathrm{C}$ levels are affected by serum TSH in primary hypothyroidism and in $\mathrm{CH}(24,25,26,27)$. While $\mathrm{Cr}$ level is decreased in patients with primary hypothyroidism after T4 replacement therapy, it remains unchanged in central hypothyroidism after the same therapy (24). Asami et al (25) have shown that in infants with $\mathrm{CH}$, the transient increase in serum $\mathrm{Cr}$ level disappears after T4 replacement. The possible mechanism suggested for decreased serum $\mathrm{Cr}$ after $\mathrm{T} 4$ replacement is that this treatment leads to increases in serum levels of vascular endothelial factor (VEGF) and insulin-like growth factor-1 (IGF-1). VEGF and IGF-1 are mediators that recover endothelial function and renal blood flow. Also these mediators may improve renal function in $\mathrm{CH}$ after T4 replacement (28). It has been indicated that high levels of serum $\mathrm{Cr}$ kinase, irrelevant to rhabdomyolysis, which were induced by severe hypothyroidism returned to normal values after replacement therapy (25).

Our results showed normal renal function in wellcontrolled $\mathrm{CH}$ patients. Using various equations to measure GFR, no difference was observed in GFR levels between $\mathrm{CH}$ patients and age- and height-matched healthy children in the present study. We could show that appropriate management of $\mathrm{CH}$ newborns maintains renal function in the normal range. Nonetheless, the mean values for FENa and FEK were found to be higher in our patients as compared with the control group.

It has been proposed that FENa can be used as a marker in assessing acute kidney injury $(29,30)$. Decreasing $K$ excretion and increasing $\mathrm{Na}$ excretion have been reported in CKD as well (31). Abnormal FENa and FEK values are reported to occur in different chronic diseases accompanied by CKD such as beta-thalassemia major, hydronephrosis, and renal artery stenosis, as well as in small for gestational age newborns $(32,33,34,35)$. We demonstrated increased FENa and FEK but normal FEMg values and normal urine $\mathrm{MA} / \mathrm{Cr}$ and urine $\mathrm{Ca} / \mathrm{Cr}$ ratios in $\mathrm{CH}$ patients. The increased FENa and FEK levels in our patients demonstrate that some degree of renal tubular impairment is present in these patients. Mild impairment in tubular function may not be detected by determining GFR and even by testing for microalbuminuria. We measured urine MA using the turbidimetric method. Using 
more accurate methods may increase the chance of detecting microalbuminuria in the early stages of CKD. The role of T4 in kidney growth has been confirmed. Triiodothyronine (T3) is the main mediator in apoptotic and proliferative effects of the thyroid hormones at the cellular level $(36,37)$. In addition, T3 is responsible for proximal tubule development (38). Whether replacing T3 changes the function and morphology of proximal tubular cells has not been studied. However, increased FENa and FEK may be a manifestation of impaired tubular maturation in $\mathrm{CH}$.

\section{References}

1. Bulbul M, Cetinkaya $\mathrm{S}$, Eksioglu $\mathrm{S}$, Ozkasap $\mathrm{S}$, Ginis T. Kidney growth in children with congenital hypothyroidism. Pediatr Nephrol 2009;24:333-340. Epub 2008 Sep 25

2. Ramos S, Goya L, Alvarez C, Pascual-Leone AM. Mechanism of hypothyroidism action on insulin-like growth factor-I and -II from neonatal to adult rats: Insulin mediates thyroid hormone effects in the neonatal period. Endocrinology 1998;139:4782-4792.

3. Escobar GM, Hierro FR. Glandula tiroides In: Argente Oliver J, Carrascosa L A, Gracia BR, Hierro FH (eds) Tratado de endocrinologia pediatrica y de la adolescencia.1st ed. EDIMSA, Madrid. 1995:455-477.

4. Gaudino R, Garel C, Czernichow P, Leger J. Proportion of various types of thyroid disorders among newborns with congenital hypothyroidism and normally located gland: a regional cohort study. Clin Endocrinol (Oxf) 2005;62:444-448.

5. Skordis N, Toumba M, Savva SC, Erakleous E, Topouzi M, Vogazianos M, Argyriou A. High prevalence of congenital hypothyroidism in the Greek Cypriot population: results of the neonatal screening program 1990-2000. J Pediatr Endocrinol Metab 2005;18:453-461.

6. Hashemipour M, Hovsepian S, Kelishadi R, Iranpour $R$, Hadian R, Haghighi S, Gharapetian A, Talaei M, Amini M. Permanent and transient congenital hypothyroidism in Isfahan-Iran. J Med Screen 2009;16:11-16.

7. Ordookhani A, Mirmiran P, Hajipour R, Hedayati M, Azizi F Screening for congenital hypothyroidism in the Islamic Republic of Iran: strategies, obstacles and future perspectives. East Mediterr Health J 2002;8:480-489.

8. Kumar J, Gordillo R, Kaskel JF, Druschel MC, Woroniecki PR. Increased prevalence of renal and urinary tract anomalies in children with congenital hypothyroidism. J Pediatr 2009;154:263-266. Epub 2008 Sep 27

9. Olivieri A, Stazi MA, Mastroiacovo P, Fazzini C, Medda E, Spagnolo A, De Angelis S, Grandolfo ME, Taruscio D, Cordeddu V Sorcini M: Study Group for Congenital Hypothyroidism. A population-based study on the frequency of additional congenital malformations in infants with congenital hypothyroidism: data from the Italian Registry for Congenital Hypothyroidism. J Clin Endocrinol Metab 2002;87:557-562.

10. Law WY, Bradley DM, Lazarus JH, John R, Gregory JW. Congenital hypothyroidism in Wales (1982-1993): demographic features, clinical presentation and effects on early neurodevelopment. Clin Endocrinol (Oxf)1998;48:201-207.

11. Mulder J, Haddad MN, Vernon K, Baum M, Quigley R. Hypothyroidism increased osmotic water permeability (Of) in the developing renal brush border membrane. Pediatr Res 2003;53:1001-1007. Epub 2003 Mar 5
12. Montiel M, Díaz F, Quesada J, Jiménez E. Ontogeny of renal renin in congenital hypothyroid rats. Life Sci 1999;65:263-269.

13. Topf JM, Murray PT. Hypomagnesemia and hypermagnesemia. Rev Endocr Metab Disord 2003:4:195-206.

14. Futrakul $P$, Yenrudi $S$, Futrakul N, Sensirivatana R, Kingwatanakul $P$, Jungthirapanich J, Cherdkiadtikul T, Laohapaibul A, Watana D, Singkhwa V, Futrakul S, Pongsin P. Tubular function and tubulointerestitial disease. Am J Kidney Dis 1999;33:886-891.

15. Futrakul N, Tosukhowong P, Valyapongpichit $Y$, Tipprukmas $\mathrm{N}$, Futrakul P, Patumraj S. Oxidative stress and hemodynamic maladjustment in chronic renal disease: a therapeutic implication. Ren Fail 2002;24:433-445.

16. JG, Munőz, A, Schneider FM, Mak HR, Kaskel F, Warady $A B$, Furth LS. New Equations to Estimate GFR in Children with CKD. J Am Soc Nephrol 2009;20:629-637. Epub 2009 Jan 21

17. Grubb A, Nyman Ulf, Björk J, Lindström V, Rippe B, Sterner G, Christensson A. Simple cystatin C-based prediction equations for glomerular filtration rate compared with the modification of diet in renal disease prediction equation for adults and the Schwartz and the Counahan-Barratt prediction equations for children. Clin Chem 2005:51:1420-1431. Epub 2005 Jun 16

18. Filler G, Lepage N. Should the Schwartz formula for estimation of GFR be replaced by Cystatin C formula? Pediatr Nephrol 2003;18:981-985. Epub 2003 Aug 13

19. Rastogi MV, La Franchi SH. Congenital hypothyroidism. Orphanet J Rare Dis 2010;5:17.

20. Gavela T, Sánchez Bayle M, Gómez Mardones G, Gallego S, Martínez-Pérez J . Pintado MT. Ultrasonographic study of kidney size in children. Nefrologia 2006;26:325-329.

21. Gowda S, Desai BP, Kulkarni SS, Hull VV, Math AKA, Vernekar NS. Markers of renal function tests. N Am J Med Sci 2010;2:170-173.

22 Stevens AL, Coresh J, Greene T, Levey SA. Assessing kidney function measured and estimated glomerular filtration rate. N Engl J Med 2006;354:2473-2483.

23. Peralta AC, Shlipak GM, Judd S, Cushman M, McClellan W, Zakai AN, Safford MM, Zhang X, Muntner P, Warnock D. Detection of chronic kidney disease with creatinine, Cystatin $\mathrm{C}$, and urine albumin-to-creatinine ratio and association with progression to end-stage renal disease and mortality. JAMA 2011;305:1545-1552. Epub 2011 Apr 11

24. Goedea LD, Wieslib P, Brändlea M, Bestmannc L, Bernaysd LR, Zwimpfere C, Schmide C. Effects of thyroxine replacement on serum creatinine and cystatin $C$ in patients with primary and central hypothyroidism. Swiss Med WKLY 2009;139:339-344.

25. Asami T, Uchiyama M. Elevated serum creatinine levels in infants with congenital hypothyroidism: reflection of decreased renal function? Acta Paediatr 2000;89:1431-1434

26. Montenegro J, Gonzalez O, Saracho R, Aguirre R, Gonzalez $\mathrm{O}$, Martinez I. Changes in renal function in primary hypothyroidism. Am J Kidney Dis 1996;27:195-198.

27. Kreisman SH, Hennessey JV. Consistent reversible elevations of serum creatinine levels in severe hypothyroidism. Arch Intern Med 1999;159:79-82.

28. Schmid C, Brandle M, Zwimpfer C, Zapf J, Wiesli P. Effect of thyroxine replacement on creatinine, insulin-like growth factor 1, acid-labile subunit, and vascular endothelial growth factor. Clin Chem 2004;50:228-231. 
Gheissari A et al.

Kidney Function in Congenital Hypothyroidism

29. Zarich S, Fang LS, Diamond JR. Fractional excretion of sodium. Exceptions to its diagnostic value. Arch Intern Med 1985;145:108-112.

30. Miller TR, Anderson RJ, Linas SL, Henrich WL, Berns AS, Gabow PA, Schrier RW. Urinary diagnostic indices in acute renal failure: a prospective study. Ann Intern Med 1978;89:47-50

31. Alcázar Arroyo R. Electrolyte and acid-base balance disorders in advanced chronic kidney disease. Nefrologia 2008;28:87-93.

32. Mohkam M, Shamsian BS, Gharib A, Nariman S, Arzanian MT. Early markers of renal dysfunction in patients with beta-thalassemia major. Pediatr Nephrol 2008:23:971-976.

33. Basioti M, Giapros V, Kostoula A, Cholevas V, Andronikou S. Growth restriction at birth and kidney function during childhood. Am J Kidney Dis 2009;54:850-858. Epub 2009 Jul 23
34. Chandar J, Abitbol C, Zilleruelo G, Gosalbez R, Montané B, Strauss J. Renal tubular abnormalities in infants with hydronephrosis. J Urol 1996;155:660-663.

35. Liaño F, Gámez C, Pascual J, Teruel JL, Villafruela JJ, Orte L, Ortuño J. Use of urinary parameters in the diagnosis of total acute renal artery occlusion. Nephron 1994;66:170-175.

36. Tata JR. Amphibian metamorphosis as a model for the developmental actions of thyroid hormones. Mol Cell Endocrinol 2006:246:10-20. Epub 2006 Jan 4

37. Su Y, Damjanovski S, Shi Y, Shi YB. Molecular and cellular basis of tissue remodeling during amphibian metamorphosis. Histol Histopathol 1999;14:175-183.

38. Ohmura T, Katyal SL, Locker J, Ledda-Columbano GM, Columbano A, Shinozuka $H$. Induction of cellular DNA synthesis in the pancreas and kidneys of rats by peroxisome proliferators, 9-cis retinoic acid, and 3,3', 5triiodo-L-thyronine. Cancer Res 1997;57:795-798. 